\title{
Sífilis secundaria nodular en paciente VIH positivo simulando linfoma cutáneo
}

\author{
O. BANIANDRÉS RODRÍGUEZ, O. NIETO PEREA, L. MOYA ALONSO, \\ R. CARRILLO GIJÓN ${ }^{1}$, A. HARTO CASTAÑO
}

Servicios de Dermatología y ${ }^{1}$ Anatomía Patológica. Hospital Ramón y Cajal. Madrid

\author{
NODULAR SECONDARY SYPHILIS IN A HIV PATIENT MIMICKING
}

CUTANEOUS LYMPHOMA

\section{RESUMEN}

Describimos el caso de un hombre de 61 años que presentaba placas infiltradas en el pecho, espalda, cara y cuello desde hacía un mes, junto con adenopatías axilares. La primera sospecha clínica fue de un linfoma primariamente cutáneo. Durante el ingreso el paciente comienza con febrícula, lesiones hiperqueratósicas palmoplantares, una placa depapilada lingual y alopecia en claros. Ante la sospecha de sífilis secundaria pedimos serología luética que nos confirma el diagnóstico. También presentaba una serología VIH positiva.

La sífilis secundaria con un patrón nodular es una forma atípica descrita hace más de 20 años y desde entonces sólo se han publicado pocos casos, cuya sospecha inicial incluían procesos linfoproliferativos malignos. Este patrón se ha encontrado tanto en pacientes VIH positivos como negativos. Discutimos las formas atípicas, la respuesta serológica y las pautas de tratamiento para la sífilis secundaria en pacientes VIH positivos.

PALABRAS CLAVE: Sífilis secundaria. VIH.
ABSTRACT

We report the case of a 61-year old man who, already for a month, had infiltrated plaques on the chest, back, neck and face as well as axilar lymphadenopathy, bearing a striking resemblance to lymphoma. During his stay in the hospital he had fever, sore throat, macules on the palms and soles and a depapilated plaque on the tongue and alopecia. A test for syphilis confirmed the diagnosis. The HIV serology was also positive.

The nodular secondary syphilis is an unusual form that was first documented more than 20 years ago. Since then, only a few cases have been reported in which the first diagnosis included lymphoreticular malignancy. This form of secondary syphilis was found in the HIV-infected as well as non-infected patients. We discuss the atypical clinical course, the inappropriate serological reactions and the therapy in HIV infected patients with secondary syphilis.

KEY WORDS: Syphilis. HIV.

Baniandrés Rodríguez, O, Nieto Perea O, Moya Alonso L, Carrillo Gijon R, Harto Castaño A. Sífilis secundaria nodular en paciente VIH positivo simulando linfoma cutáneo. An Med Interna (Madrid) 2004; 21: 241-243.

\section{INTRODUCCIÓN}

Actualmente se observa un reducido número de casos de sífilis secundaria debido al cambio de comportamientos sexuales en relación con el SIDA y la eficacia del tratamiento con penicilina; por tanto para diagnosticar a la "gran simuladora" se debe mantener un alto grado de sospecha clínica. Nosotros describimos un patrón atípico, tipo nodular, de sífilis secundaria, y comentamos algunas peculiaridades clínicas, serológicas y terapéuticas de la sífilis en los pacientes VIH positivos.

\section{CASO APORTADO}

Se trata de un hombre de 61 años, sin otros antecedentes personales que una fístula perianal valorada por el Servicio de Cirugía. Presentaba desde hacía un mes placas infiltradas no pruriginosas, en pecho, espalda, cuello y cara (Fig. 1); junto con adenopatías axilares, de consistencia elástica de 2-3 cm de diámetro, sin otros datos clínicos ni analíticos de interés. Nuestra primera sospecha diagnóstica fue de un linfoma primariamente cutáneo. Durante el ingreso, el paciente comenzó con febrícula, odinofagia y malestar general, observándose en la exploración lesiones hiperqueratósicas en palmas y plantas, junto a una placa depapilada en el dorso lingual y alopecia en claros;

Trabajo aceptado: 17 de noviembre de 2003

Correspondencia: Ofelia Baniandrés Rodríguez. C/ Dulcinea, 23, Bajo A. 28020 Madrid. e-mail: Ofelia_baniandres@yahoo.es. 


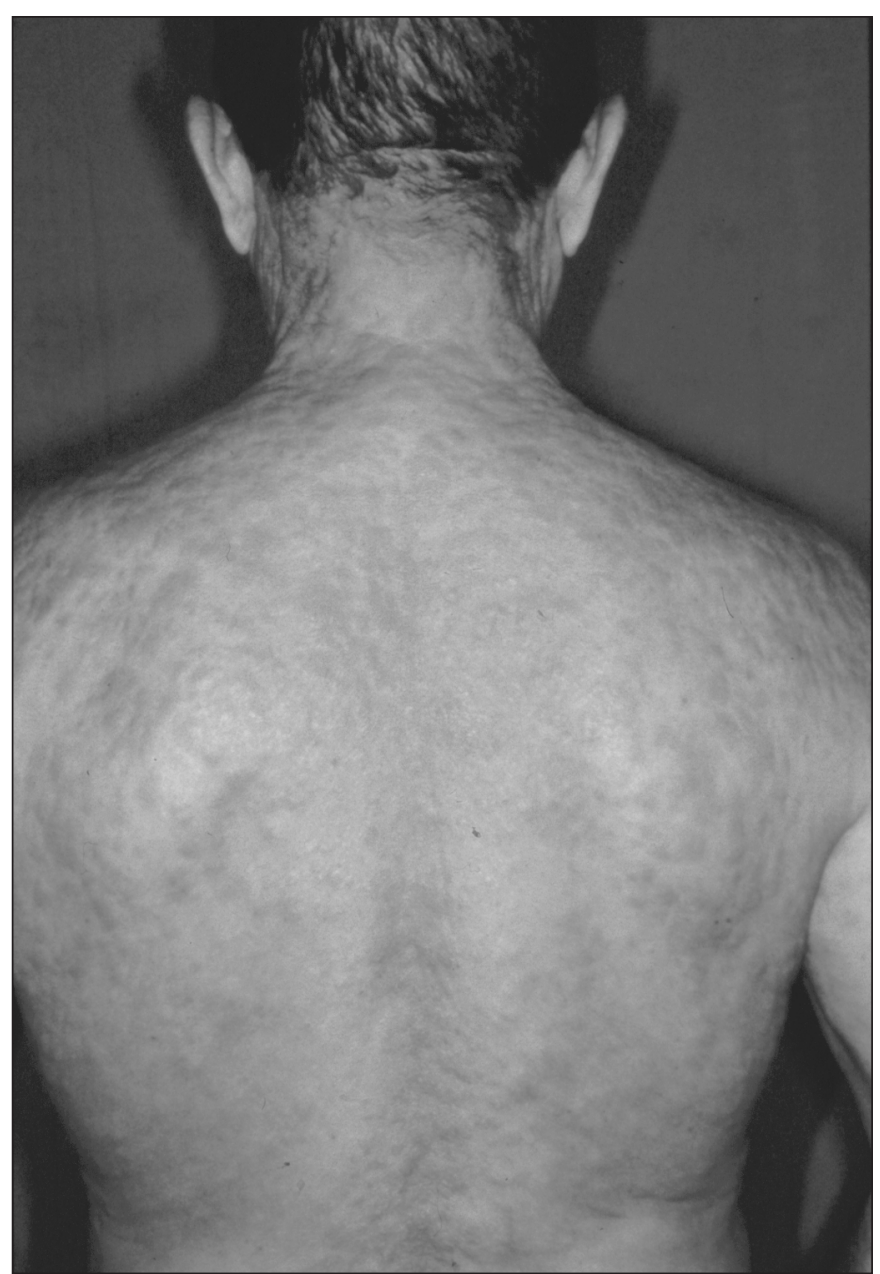

Fig. 1. Erupción formada por numerosas placas infiltradas, no confluyentes, eritematosas, en espalda y cuello.

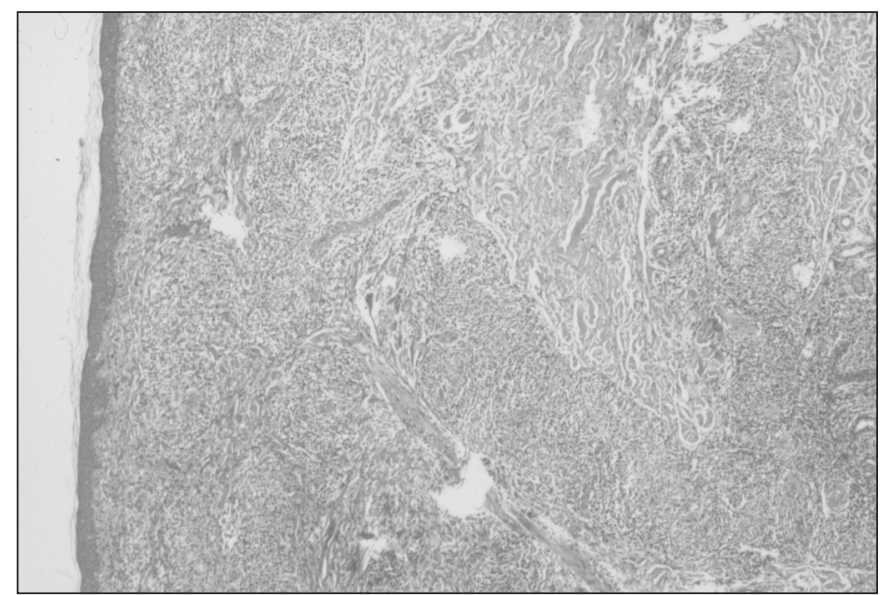

Fig.2. Infiltrado linfohistiocitario muy denso, con células plasmáticas, en dermis superficial y profunda que invade los accini de las glándulas ecrinas.

ante la sospecha de sífilis secundaria pedimos serología luética que resultó positiva tanto para la prueba reagínica (RPR 1/32), como para la treponémica (IgG Elisa +, hemoaglutimación + a 5120). Reinterrogado al paciente sobre sus hábitos sexuales, refirió haber tenido relaciones homosexuales, así que supusimos que la fístula perianal que había presentado unos meses antes, coincidía con el chancro prima- rio. Entre las pruebas complementarias realizadas se encontró una serología positiva para el VIH con un total de $273 \mathrm{CD} 4$; en el resto de las pruebas pedidas (TAC, inmunofenotipo en sangre periférica, EEF, beta 2 microglobulina, células de Sézary en sangre periférica) no se encontraron datos de malignidad. En la biopsia cutánea se observaba un infiltrado linfohistiocitario muy denso que ocupaba toda la dermis (Fig. 2), formado por acúmulos de histiocitos epiteloides y abundantes linfocitos y células plasmáticas. Las técnicas de tinciones especiales para identificar hongos y micobacterias (ac.Schiff, Ziehl-Neelsen) fueron negativas.

Ante el diagnóstico de sífilis secundaria en un paciente VIH positivo, se le realizó una punción lumbar para descartar la afectación del SNC (no alteraciones celulares en el LCR, BQ normal, VDRL negativo e IgG ELISA negativo). Se instauró tratmiento con 2,4 millones de unidades de penicilina $\mathrm{G}$ benzatina durante 3 semanas consecutivas, sin presentar reacción de Jarisch-Herxheimer, y en controles posteriores se observó una lenta resolución de las lesiones con un progresivo descenso de los títulos serológicos luéticos.

\section{DISCUSIÓN}

Un alto porcentaje de pacientes VIH positivos presenta una serología luética positiva (1), aunque sólo una pequeña parte ha manifestado clínica luética activa. Se discute si esta relación entre el VIH y el Treponema pallidum es únicamente epidemiológica, ya que ambas son ETS, o existe una interacción patogénica entre ambos microorganismos. Se ha demostrado que el chancro $1^{\circ}$ facilita la infección por VIH. Además el VIH favorece la progresión más rápida de la sífilis por el empeoramiento de la inmunidad celular y el descenso de los linfocitos T helper.

Además del aumento de prevalencia de la sífilis en pacientes VIH positivos, a menudo estos pacientes presentan una clínica luética atípica, se han observado úlceras genitales múltiples persistentes (2), erosiones orales y lesiones vesiculosas. Estas manifestaciones atípicas son más probables cuando presentan niveles de CD4<150 (3).

También se ha descrito que es 60 veces mayor (1) el riesgo de presentar lesiones ulceradas acompañadas de fiebre y afectación ocular y oral, con un sustrato histológico de vasculitis, la denominada sífilis maligna (4).

Rara vez la sífilis $2^{a}$, como observamos en nuestro paciente, se manifiesta como placas o nódulos infiltrados mostrando en la histología una infiltración granulomatosa e incluso granulomas sarcoideos, siendo estos hallazgos más típicos de la sífilis $3^{\text {a }}$ (5). Este patrón nodular se describió hace más de 20 años (6) y desde entonces se han publicado ocasionalmente otros casos (5,7-12) en los que también se sospechó inicialmente un linfoma cutáneo. Se han observado formas de sífilis $2^{\mathrm{a}}$ nodular tanto en pacientes VIH positivos como negativos, e incluso se han descrito formas de sífilis $2^{\mathrm{a}}$ nodular localizadas (13). Algunos autores sugieren que estas lesiones granulomatosas representan una reacción específica de hipersensibilidad al Treponema pallidum (14) y consideran que es una transición a una sífilis $3^{\mathrm{a}}(7)$ que en los pacientes VIH positivos puede estar acelerada.

Durante la sífilis $2^{\mathrm{a}}$ las pruebas treponémicas y las no treponémicas son positivas y los niveles de VDRL suelen ser iguales o mayores de 1/32. Menos del $1 \%$ de los pacientes presentan un VDRL negativo; hay que tener también en cuenta que rara vez los falsos positivos exceden títulos de 1/8. Las pruebas treponémicas se mantienen positivas tras el trata- 
miento por lo que no sirven para determinar el estado de la infección. Parece que la mayoría de los pacientes VIH positivos tienen una respuesta serológica normal, pero también se observan falsos positivos de VDRL y niveles más altos de los esperados en ausencia de reinfección debido a la activación policlonal de los linfocitos B. A su vez, también se han descrito retrasos en la positividad o falsos negativos del VDRL (3), TPHA, FTA-ABS (15) e incluso en pruebas muy sensibles como el test 19-IgM-FTA-ABS $(1,16)$ que puede explicarse por el fenómeno prozona: el exceso de anticuerpos producidos por los linfocitos B alterados impiden la reacción antígenoanticuerpo en los test estándar (1). Por tanto, cuando la clínica es muy sugestiva de lúes pero la serología es negativa, se recomienda realizar serologías luéticas seriadas y llevar a cabo tests alternativos como buscar el ADN del treponema pallidum por PCR (17), o a través de la técnica de inmunoperoxidasa (18) o de la inmunofluorescencia directa que resultan mucho mas sensibles que las tinciones de plata (WarthinStarry).

Otro aspecto importante de la sífilis $2^{\mathrm{a}}$ en VIH positivos, es descartar la afectación del SNC; ya que parece que el VIH acelera los estadios de la sífilis y pacientes con un periodo de latencia de meses pueden desarrollar neurolúes y ésta puede

\section{Bibliografía}

1. Schöfer H, Imhof M, Thoma-Greber E, Brockmeyer NH, Hartmann M, Gerken G, et al. The German AIDS Study Group (GASG). Active syphilis in HIV infection: a multicentre retrospective survey. Genitourin Med 1996; 72: 176-181.

2. Rompalo AM, Joesoef MR, O'Donnell JA, Augenbraun M, Brady W, Radolf JD et al. Clinical manifestations of early syphilis by HIV status and gender: results of the syphilis and HIV study. Sex-Transm-Dis 2001; 28: 158-65.

3. Glover RA, Piaquadio DJ, Kern S, Cockerell CJ. An unusual presentation of secondary syphilis in a patient with human inmunodeficiency virus infection. Arc Dermatol 1992; 128: 530-534.

4. Romero-Jiménez MJ, Suárez Lozano I, Fajardo Picó JM, Barón Franco B. Sífilis maligna paciente infectado por el virus de la inmunodeficiencia humana (VIH): descripción de un caso y revisión de la literatura. An Med Interna (Madrid) 2003; 20: 373-376

5. Adriaans B.An erythematous nodular eruption. Secondary syphilis. Arch Dermatol 1992; 128: 978-9,981.

6. Graham WR, Duvic M. Nodular secondary syphilis. Arch Dermatol 1982; 118: 205-206.

7. Sapra S, Weatherhead L. Extensive nodular secondary syphilis. Arch Dermatol 1989; 125: 1666-1669.

8. Papini M, Bettacchi A, Guiducci A. Nodular secondary syphilis. Br J Dermatol 1998; 138: 704-705.

9. Hodak E, David M, Rothem A, Bialowance M, Sandbank M. Nodular secondary syphilis mimicking cutaneous lymphoreticular process. J Am Acad Dermatol 1987; 17: 914-7.

10. Pavithran K. Nodular secondary syphilis. Int J Dermatol 1991; 30: 799800.

11. Liotta EA,Turiansky GW,Berberian BJ,Sulica VI, Tomaszewski MM. Unusual presentation of secondary syphilis in $2 \mathrm{HIV}-1$ positive patients. Cutis 2000; 66: 383-6,389.

12. Harden D, Keeling JH. Papular and nodular lesions of the scalp, face, and neck. Secondary syphilis. Arch Dermatol 1997; 133: 1027-1030.

13. Vibhagool C, Raimer SS, Sanchez RL. A nodule on the lip. Nodular ser más grave que en pacientes VIH negativos. Por ello se recomienda realizar punción lumbar ya en pacientes con lúes $1^{\mathrm{a}}, 2^{\mathrm{a}}$ o latente de menos de un año incluso en ausencia de síntomas neurológicos. La valoración del LCR puede ser a su vez difícil pues una elevación de células mononucleares o de las proteínas en el LCR puede deberse a diferentes causas tumorales o infecciosas. Sólo la positividad del VDRL, o la identificación del Treponema pallidum en el LCR por PCR sería diagnóstico de neurosífilis. Por otro lado, se han descrito pacientes con neurolues y VDRL negativo (19).

La pauta recomendada para la sífilis precoz es de 2,4 millones de unidades de penicilina benzatina en unidosis, previamente se aconseja dar profilaxis para evitar la reacción de Jarisch-Herxheimer. Como alternativa al tratamiento estándar, Hook y cols. han descrito una eficacia similar con eritromicina en el periodo de incubación y durante la sífilis precoz (20,21). En cuanto a pacientes VIH positivos, existe discusión sobre cual es la pauta más apropiada, las recomendaciones varían entre tratar de la misma manera que a los pacientes VIH negativos (22-24), siempre una vez descartada la afectación neurológica, a dosis mayores, o bien con pautas de neurolúes (12-24 millones de unidades/día i.v. de penicilina $\mathrm{G}$ acuosa durante 10-14 días). secondary syphilis. Arch Dermatol 1996; 132: 822-3,825-6.

14. Lantis LR, Petrozzi JW, Hurley HJ. Sarcoid granuloma in secondary syphilis. Arch Dermatol 1969; 99: 748-52.

15. Fowler VG, Maxwell GL, Myers SA, Shea CR, Livengood CN, Prieto VG, et al. Failure of benzathine penicillin in a case of seronegative secondary syphilis in a patient with acquired immunodeficiency syndrome: case report and review of the literature. Arch-Dermatol 2001; 137: $1374-6$.

16. Wicher K, Horowitz HW, Wicher V. Laboratory methods of diagnosis of syphilis for the beginning of the third millennium. Microbes Infection 1999; 1 : 1035-49.

17. Marfin AA, Liu H, Sutton MY, Steiner B, Pillay A, Markowitz LE. Amplification of the DNA polymerase I gene of Treponema pallidum from whole blood of persons with syphilis. Diagn Microbiol Infect Dis 2001; 40: 163-6.

18. Phelps RG, Knispel J, Tu ES, Cernaniu G, Saruk M. Immunoperoxidase technique for detecting spirochetes in tissue sections: comparison with other methods. Int J Dermatol 2000; 39: 608-13.

19. Golden MR, Marra CM, Holmes KK. Update of syphilis: resurgence of an old problem. JAMA 2003; 290: 1510-4.

20. Hook E III, Stephens J, Ennis DM. Azithromycin compared with penicillin G benzathine for treatment of incubating syphilis. Ann Intern Med 1999; 131: 434-437.

11. Hook E III, Martin DH, Stephens J, Smith BS, Smith K. A randomized, comparative pilot study on azithromycin versus benzathine penicillin G for treatment of early syphilis. Sex Transm Dis 2002; 29: 486-490

21. Anonymus. Syphilis primaire et secondaire. Epidemiologie, diagnostic, traitment. Ann Dermatol Venereol 2000; 127 (Spec No 1): A 136-43.

22. 1998 guidelines for treatment of sexually transmitted diseases. Centers for Disease Control and Prevention. MMWR Morb Mortal Wkly Rep 1998; 47 (RR-1): 1-111.

23. Augenbraun MH. Teatment of syphilis 2001: Nonpregnant Adults. CID 2002: 35 (Supl. 2). 